Open Access

Original Article

\title{
Genetic variants of calcium sensing receptor gene and risk of colorectal cancer: A case-control study
}

\author{
Ayat Badr Al-Ghafari
}

\begin{abstract}
Objectives: To determine the role of two genetic variants, (rs3804594) and (rs1801725), in calcium sensing receptor (CASR) gene with colorectal cancer (CRC) risk in patients visited King Abdulaziz University hospital (KAUH) in Jeddah, Saudi Arabia.

Methods: Genomic DNA was extracted, by commercial DNA extraction kit, from whole blood of 100 CRC patients and 124 controls who visited KAUH from January 2016 to September 2016. Then genotype and allele distributions of both variants were determined by PCR-RFLP and DNA sequencing techniques. All statistical analyses were performed by unpaired t-test and $P$-values $<0.05$ were considered statistically significant.
\end{abstract}

Results: Data obtained from $\chi^{2}$ test showed that intron 4 variant in CASR gene was distributed $100 \%$ normally in the 224 participants, however, exon 7 variant showed $100 \%$ homozygous distribution in the controls; whereas, in CRC patients it was distributed equally into $50 \%$ heterozygous and $50 \%$ homozygous with no detection for wild type.

Conclusion: Intron 4 variant (rs3804594) in CASR gene is not correlated to CRC risk. However, more investigations are needed to elucidate the role of CASR gene exon 7 (rs1801725) variant in CRC development as the current results are not definitive.

KEYWORDS: CASR gene (rs1801725) variant, CASR gene (rs3804594) variant, Colorectal cancer risk, Saudi Arabia.

How to cite this:

doi: https://doi.org/10.12669/pjms.35.2.38

Al-Ghafari AB. Genetic variants of calcium sensing receptor gene and risk of colorectal cancer: A case-control study. Pak J Med Sci. 2019;35(2):448-453. doi: https://doi.org/10.12669/pjms.35.2.38

This is an Open Access article distributed under the terms of the Creative Commons Attribution License (http://creativecommons.org/licenses/by/3.0), which permits unrestricted use, distribution, and reproduction in any medium, provided the original work is properly cited.

1. Ayat Badr Al-Ghafari,

a) Department of Biochemistry, Faculty of Science,

King Abdulaziz University,

Jeddah, Saudi Arabia.

b) Experimental Biochemistry Unit,

c) Cancer and Mutagenesis Unit,

King Fahd Medical Research Center,

King Abdulaziz University,

Jeddah, Saudi Arabia.

Correspondence:

Dr. Ayat B. Al-Ghafari, PhD,

Associate Professor of Biomedical Sciences,

Biochemistry Department, Faculty of Science,

King Abdulaziz University,

P.O.Box (8795), Jeddah (23817),

Saudi Arabia.

Email: abalghafari@kau.edu.sa

* Received for Publication:

* Corrected and Edited:

* Accepted for Publication:
October 23, 2018

December 15, 2018

February 14, 2019

\section{INTRODUCTION}

The calcium ion $\left(\mathrm{Ca}^{2+}\right)$ is very important in the regulation of several signaling pathways that are contributed to many cellular processes such as proliferation, differentiation, apoptosis, gene expression, and fluid and hormones secretions. ${ }^{1}$ The $\left(\mathrm{Ca}^{2+}\right)$ homeostasis is monitored under the effect of certain G-protein coupled receptor- family $\mathrm{C}$ known as calcium sensing receptor (CASR). ${ }^{2}$ The highest expression of CASR is usually seen in the kidney and the chief cells in parathyroid tissues. However, other organs may express CASR on their surfaces such as colon. ${ }^{3}$ In the colon, CASR enhances the differentiation of colonocytes which in turn reduces the formation of neoplasia in the colon. ${ }^{4}$ Moreover, it inhibits fluid and electrolyte secretion, which could potentially 
serve as a treatment for diarrheal disease. ${ }^{5}$ It may also help the ions of $\mathrm{Ca}^{2+}$ to upregulate proteins which modulate duodenal $\mathrm{Ca}^{2+}$ absorption in vivo, although the certain molecular mechanisms behind this physiological process are not clear. ${ }^{6}$ The human CASR gene is located on chromosome 3q13.33-q21.1 and contains 11 exons, two promoters and two 5'-untranslated exons (exon 1A and 1B) that yield alternative transcripts, but encoding the same protein. ${ }^{7}$ As many other genes, any genetic variations in the CASR gene, either in the form of mutations or single nucleotide polymorphisms (SNPs), can result in a loss or gain of function, which in turn lead to significant alterations in circulating concentrations of calcium that is associated not only with disorders of the parathyroid glands, but also with other conditions such as bone disorders, vascular disorders, and cancer. ${ }^{1}$

Colorectal cancer (CRC) is considered one of the most prevalent cancers with high incidence and morbidity rate worldwide. According to the latest report from the National Cancer Registry (NCR) at King Faisal Specialist Hospital and Research Centre (KFSHRC) in Saudi Arabia, CRC represents the first and the third most common cancer types among males and females, respectively. ${ }^{8}$ Although significant advances in the diagnosis and treatment have been made for CRC patients in Saudi Arabia, the overall 5-year survival rate was $(44.6 \%)$ for the period 1994-2004 with a high percentage of distant metastasis $(28.4 \%)$ in patients at the time of presentation and rectal cancer represented $(41 \%)$ of all colorectal cancer cases diagnosed in $2010 .^{8}$ This poor overall 5-year survival rate is partially due to the lifestyle such as diet and physical activity and partially due to acquired drug resistance. ${ }^{9}$

The CASR is able to respond to a variety of ligands, including polyvalent cations and amino acids. Therefore, any changes of $\mathrm{pH}$ and ionic strength that occur in cancer cells may affect the activity of the CASR and subsequently affect its capability to integrate several signaling pathways. Most of the published articles revealed that CASR expression play a protective role in CRC patients through several mechanisms such as binding toxic secondary bile acids and/or ionized fatty acids and neutralizing them in form of insoluble calcium soaps, ${ }^{10}$ or by affecting several signaling transductions such as stimulating cell differentiation, inducing apoptosis and inhibiting proliferation. ${ }^{11}$ To the best of our knowledge, no studies have been conducted to correlate the relation between genetic polymorphisms in CASR gene and risk of CRC in Saudi patients. Therefore, this study was aimed to determine the genetic distribution and allele frequency of two SNPs in CASR gene in drug-resistant CRC patients that are routinely visiting King Abdulaziz University Hospital (KAUH) to reveal the possible effect, if present, on the pathogenesis of CRC.

\section{METHODS}

In this study, 100 CRC patients and 124 controls were included. The purpose of the research was explained and a written consent of the participants as well as their answers on a questionnaire were obtained. The study was approved by the biomedical ethics unit at faculty of medicine, King Abdulaziz University (KAU) (reference no. 378-17). Several anthropometric measurements such as body weight, height, body mass index (BMI), waist and hip circumference, and waist-to hip-ratio (WHR) were calculated for all participants. All blood samples were drawn into lavender top vacutainers containing anticoagulants (EDTA) and were obtained from oncology clinics at King Abdulaziz University Hospital (KAUH) in Jeddah, KSA from the period January 2016 to September 2016. Genomic deoxyribonucleic acid (gDNA) was extracted from peripheral blood leukocytes in whole blood samples using QIAamp DNA Mini Kit (QIAGEN, Hilden, Germany) following the manufacturer's instructions. The quality of each extracted DNA sample was assessed by measuring the absorbance at two wavelengths (260 and 280).

Amplification and genotyping of intron 4 polymorphism (rs3804594) in CASR gene: For a $25 \mu \mathrm{l}$ PCR reaction, $2 \mu \mathrm{l}$ genomic DNA $(100 \mathrm{ng} / \mu \mathrm{l})$, $12.5 \mu 1$ HotStart-IT® FideliTaq ${ }^{\text {TM }}$ PCR Master Mix (2X) (catalog no. 71156, Affymetrix, USA), $8.5 \mu \mathrm{l}$ RNase free water, and $1 \mu \mathrm{l}$ of $(100 \mathrm{pmol} / \mathrm{ul})$ of forward primer: 5'-CAAGGACCTCTGGACCTCCCTTTGC-3' and reverse primer: 5'-GACCAAGCCCTGCACAGTGCCCAAG-3') were used. The tubes that contain the PCR mixture were centrifuged at $5000 \mathrm{rpm}$ for $10 \mathrm{~min}$. The PCR thermocycler conditions were as follows: initial denaturation at $94^{\circ} \mathrm{C}$ for 5 minutes. Followed by 35 cycles of denaturation at $94^{\circ} \mathrm{C}$ for 30 seconds, annealing at $68^{\circ} \mathrm{C}$ for 30 seconds, and finally an extension at $72^{\circ} \mathrm{C}$ for one minute. A final extension step was performed at $72^{\circ} \mathrm{C}$ for 5 minutes. ${ }^{12}$ The samples were then run on $2 \%$ agarose gel to visualize the amplified PCR products (320 bp). The genotyping examination of all PCR samples for intron 4 poly- 
morphism (rs3804594) in CASR gene was done by DNA sequencing technique using the sequencer (3130 Genetic Analyzer, serial number: 313001026). The sequencing was done at Centre of Excellence in Genomic Medicine Research (CEGMR) in King Fahd Medical Research Centre (KFMRC), KAU, Jeddah, Saudi Arabia.

Amplification and genotyping of exon 7 polymorphism (rs1801725) in CASR gene: For a 25 $\mu 1$ PCR reaction, $2 \mu \mathrm{l}$ genomic DNA $(100 \mathrm{ng} / \mu \mathrm{l})$, $12.5 \mu$ l HotStart-IT® FideliTaq ${ }^{\text {TM }}$ PCR Master Mix (2X) (catalog no. 71156, Affymetrix, USA), $8.5 \mu 1$ RNase free water, and $1 \mu \mathrm{l}$ of $(100 \mathrm{pmol} /$ ul) of forward primer:5'-CTGAGCTTTGATGAGCCTCAGAAGGAC-3' and reverse primer: 5 '-CACTGATGACAAGCTCTGTGAACTGGA-3')were used. The tubes that contain the PCR mixture were centrifuged at $5000 \mathrm{rpm}$ for 10 min. The PCR thermocycler conditions were as follows: initial denaturation at $94^{\circ} \mathrm{C}$ for $5 \mathrm{~min}$ utes. Followed by 35 cycles of denaturation at $94^{\circ} \mathrm{C}$ for one minute, annealing at $63^{\circ} \mathrm{C}$ for one minute, and finally an extension at $72^{\circ} \mathrm{C}$ for one minute. A final extension step was performed at $72{ }^{\circ} \mathrm{C}$ for 5 minutes. ${ }^{13}$ The samples were then run on $2 \%$ agarose gel with ethidium bromide to visualize the amplified PCR products (269 bp).The genotype distributions of exon 7 polymorphism (rs1801725) in CASR gene were determined by restriction fragments length polymorphism (RFLP) procedure. In Eppendorf tube, $10 \mu 1$ of PCR product, $17 \mu 1$ nuclease-free water, $2 \mu 110 x$ FastDigest green buffer and $1 \mu l$ of Thermo Scientific FastDigest Hin1I (catalog no. FD0474, Thermo Scientific, USA) were added. Then the mixture was mixed by pipetting gently, and was spin down for few seconds. The incubation was done at $37^{\circ} \mathrm{C}$ in a heat block for 20 minutes with no inactivation step.
Statistical analysis: All statistical analyses were performed on GraphPad Prism version 5.00 (San Diego California, USA). A $\chi^{2}$ test was used to compare the allele frequency and genotype distribution of each variant following HardyWeinberg equilibrium. Unpaired t-test was used to compare between two physical parameters. $P$-values of $<0.05$ were considered as statistically significant.

\section{RESULTS}

Anthropometric measurements of study participants: In this study, a total of 224 subjects, $\mathrm{n}=100$ CRC patients and $\mathrm{n}=124$ healthy controls, were included. Unpaired t-test showed that there was highly significant difference between patients and controls in age, weight, and BMI $(P<0.0001)$ only as shown in Table-I.

Genotype distribution and allele frequency of intron 4 polymorphism (rs3804594) in CASR gene: The amplified fragments showed a size of $320 \mathrm{bp}$. To determine the polymorphic genotypes, the PCR products were analyzed with DNA sequencing technique.The normal (TT) genotype produced only one band of size $320 \mathrm{bp}$. The heterozygous (TC) genotype produced three fragments of sizes 60,260 , and $320 \mathrm{bp}$, and the homozygous (CC) genotype produced two fragments of sizes 60 and 260 bp (Fig.1). The DNA sequencing analysis of SNP (rs3804594) revealed that all subjects showed $100 \%$ wild type with no reported homozygous or heterozygous genotypes. Therefore, this SNP is rare in the study population and therefore, cannot be correlated with the CRC risk.

Genotype distribution and allele frequency of exon 7 polymorphism (rs1801725)in CASR gene: The amplified fragments showed a size of 269

Table-I: Comparison of the physical measurements for patients and controls.

\begin{tabular}{lccc}
\hline Physical measurement & CRC Patients $(n=100)$ & Controls $(n=124)$ & P-value \\
\hline Age (years) & $55.73 \pm 1.51$ & $40.84 \pm 0.78$ & $<0.0001$ (HS) \\
Height $(\mathrm{cm})$ & $165.1 \pm 1.15$ & $168.0 \pm 0.92$ & $>0.05$ (NS) \\
Weight $(\mathrm{Kg})$ & $73.2 \pm 1.94$ & $83.6 \pm 1.44$ & $<0.0001$ (HS) \\
Body Mass Index $\left(\mathrm{Kg} / \mathrm{m}^{2}\right)$ & $26.8 \pm 0.69$ & $29.7 \pm 0.49$ & $<0.0001$ (HS) \\
Waist $(\mathrm{cm})$ & $100.3 \pm 2.43$ & $101.8 \pm 1.72$ & $>0.05$ (NS) \\
Hip $(\mathrm{cm})$ & $110.0 \pm 2.30$ & $108.0 \pm 1.58$ & $>0.05$ (NS) \\
Waist to hip ratio & $0.917 \pm 0.02$ & $0.948 \pm 0.01$ & $>0.05$ (NS) \\
\hline
\end{tabular}

All data are represented as mean \pm standard error of mean, The $P$-values were calculated by unpaired $t$-test, HS: highly significant, NS: no significant difference. 


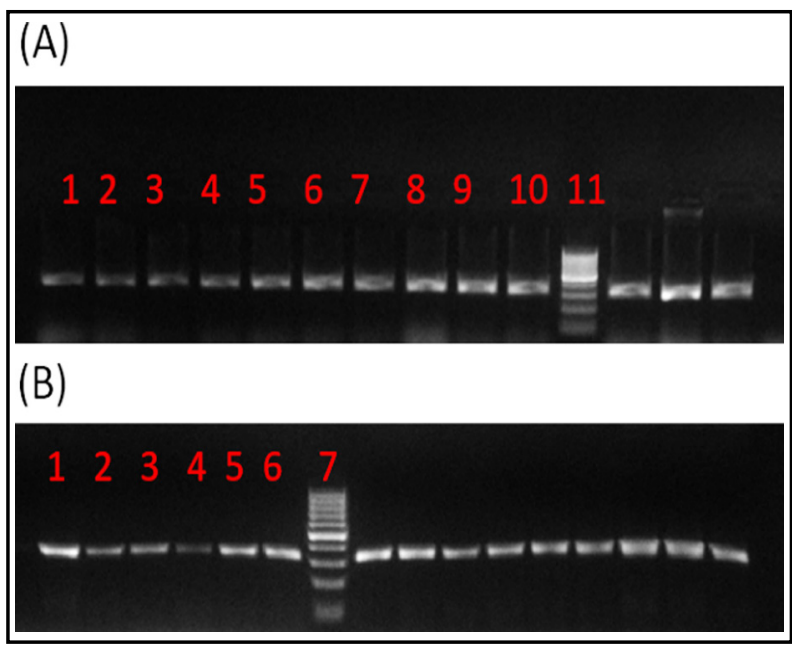

Fig.1: Genotyping of intron 4 polymorphism (rs3804594) in CASR gene. (A) Showed the gel electrophoresis for the CRC patients, where lanes (1-10) represents the PCR products for P1-P10 (320 bp) and lane 11 represents the DNA ladder $100 \mathrm{bp}$ ). (B) Showed the gel electrophoresis for the healthy controls, where lanes (1-6) represents the PCR products for C1-C6 (320 bp) and lane 7 represents the DNA ladder $100 \mathrm{bp})$.

$\mathrm{bp}$. To determine the polymorphic genotypes, the PCR products were digested with Hin1I enzyme. The normal (GG) genotype produced two bands of sizes 128 and $241 \mathrm{bp}$. The heterozygous (GT) genotype produced three fragments of sizes 28,241 , and $269 \mathrm{bp}$, and the homozygous (TT) genotype produced only one fragment of size $269 \mathrm{bp}$ (Fig.2). The genotypic frequencies of the patients were $0 \%(n=0)$ normal $(G G), 53 \%(n=53)$ heterozygous (GT), and $47 \% \quad(n=47)$ homozygous (TT). The frequency of $\mathrm{G}$ allele was $(26.5 \%)$ and $\mathrm{T}$ allele was (73.5\%). Genotype distribution for CRC patients was out Hardy-Weinberg equilibrium (Goodness of fit $X^{2}=16.82$, degree of freedom $\left.(\mathrm{DF})=1, P<0.05\right)$. In controls, the results showed $0 \%(\mathrm{n}=0)$ normal (GG), $0 \%(n=0)$ heterozygous (GT), and 100\% $(n=124)$ homozygous (TT). The frequency of $G$ allele was $(0 \%)$ and $\mathrm{T}$ allele was $(100 \%)$. Genotype distribution for the controls was out of HardyWeinberg equilibrium (Goodness of fit $\chi^{2}=122$, $\mathrm{DF}=1, P<0.05)$. The calculation of the risk and odds ratios, Fisher's $P$-value and 95\% confidence interval by the $2 \times 2$ contingency table were impossible since no patients or controls showed normal (GG) genotype. Therefore, it was statistically difficult to correlate the genotypes distribution of this SNP with increased or decreased risk of CRC in the study population.

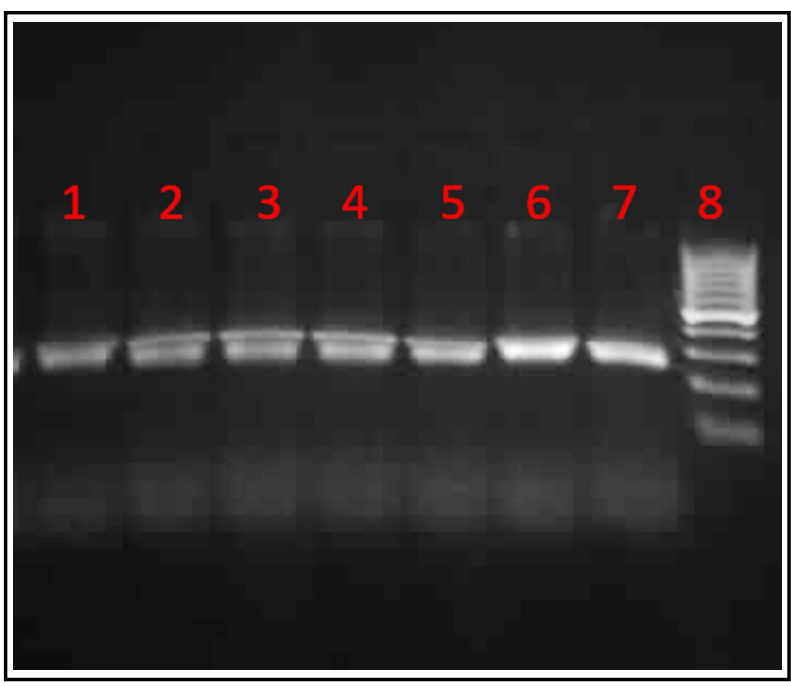

Fig.2: Genotyping of exon 7 polymorphism (rs1801725) in CASR gene. This gel represents the PCR products after digesting with Hin1I enzyme. Lanes (1-5) showed heterozygous genotypes with three bands of sizes (28, 241, and $269 \mathrm{bp}$ ). Lane 6 showed homozygous genotype with one band of size $(269 \mathrm{bp})$. Lane 8 represents the DNA ladder (100 bp).

\section{DISCUSSION}

CRC is one of the most prevalent types of cancers and a major cause of death globally. In Saudi Arabia, although many advances have been made in the diagnosis and treatment of CRC, this cancer type still ranks the first and the third most common malignancies among males and females, respectively. ${ }^{8}$ Like other types of cancers, CRC resulted from an interaction between several factors such as chemical carcinogens, genetic factors, inflammatory diseases and diet. Diet plays a major role in colorectal tumorigenesis. Several epidemiological studies showed an inverse correlation between calcium intake and the risk of tumor development. ${ }^{14,15}$ Calcium performs several important physiological processes such as cell signaling, blood clotting, muscle contraction, nerve function, enzymes activation, ions transportation across the cellular membrane, and neurotransmitters communications with other cells. ${ }^{16}$ It is known that calcium performs its function through binding to special $G$ protein -coupled receptor known as calcium sensing receptor (CASR). In cancer, CASR expression can be reduced, lost, or become activated. Moreover, the calcium signaling may differ depending on the type of cancer, stage, grade, and other factors such as in colon and parathyroid cancers (it acts as 
tumor suppressor), whereas, in breast and prostate cancers (it acts as an oncogene). ${ }^{17-20}$

Around one hundred and twelve mutations (98 missense, 6 nonsense, 8 insertion and/or deletion, and one splice mutation) have been described in the CASR mutation database and were tested for their contributions to several diseases including diabetes mellitus, kidney diseases, and parathyroid adenoma. ${ }^{12,21,22}$ However, fewer researches were conducted on CRC patients. Therefore, there is an urgent need for a better understanding of how individual ligands affect CASR-mediated signaling, and how this will in turn benefit the development of novel pharmaceutical therapies targeting the CASR in CRC. To the best of our knowledge, there are no conducted studies that determine the effect of genetic variants in CASRgene in CRC patients in Saudi Arabia. Therefore, in this study, two SNPs in CASR gene were determined in CRC patients and control subjects to reveal their implications in CRC risk. In the current study, the analysis by PCR-RFLP and DNA sequencing revealed that variant (rs3804594) in intron 4 showed a $100 \%$ wild type in our study population. Neither heterozygous nor homozygous were determined in either CRC patients or controls. On the other hand, interestingly, results showed that variant (rs1801725) in exon 7 showed 0\% normal genotype and $50 \%$ for the both genotypes (heterozygous and homozygous) in CRC patients, whereas, in controls, the results showed $100 \%$ homozygous genotype with no distribution for normal or heterozygous genotypes. Unfortunately, in both SNPs, the correlation between genotypes distribution and allele frequency for both SNPs and CRC risk was difficult to be calculated since no normal genotype cases were recorded, therefore, risk and odds ratios were not calculated by chi-square test.

Regarding the association of variant (rs3804594) in intron 4 with cancer implications, less is known about the effect of this SNP with cancer risk as most of the published results studied other SNPs in different regions (introns or exons) rather than SNP (rs3804594). In the current study, (rs3804594) was found to be normally distributed in the study population therefore, has no effect on CRC risk. However, variant (rs3804594) was found to be highly correlated with the risk of diabetes mellitus Type- 2 and diabetic nephropathy. ${ }^{12}$

On the other hand, regarding the association of variant (rs1801725) with cancer risk, in agreement with our results, Wang et al. showed that the mean calcium levels were higher in breast cancer patients compared to controls $(P<0.001)$ due to inactivating polymorphisms at rs1801725. ${ }^{23}$ Moreover, a research performed on Iranian CRC patients showed that CASR gene (rs1801725) variant is not a genetic contributor to CRC risk in the Iranian population. ${ }^{13}$ In another case-control study that was conducted to explore the possible association between (rs1801725) variant in CASR gene and CRC risk, they found no significant difference for this variant in both genotype and allele frequencies between CRC and the controls. ${ }^{24}$ Variant (rs1801725) was found to be significantly associated with clinical outcome in patients with stage four and the histological subgroup of undifferentiated neuroblastomas. Moreover, patients harboring this polymorphism had significantly lower overall and event-free survival rates than those who were homozygous for the most common allele. ${ }^{25}$

\section{CONCLUSION}

To the best of our knowledge, this is perhaps the first study that determined the effect of genetic variants in CASR gene in CRC patients in Saudi Arabia. The analysis by PCR-RFLP and DNA sequencing revealed that none of the two variants are correlated with CRC risk in Saudi patients.However, the analysis are recommended to be performed on larger population and to compare the finding of this study with the recent published data whenever it is available. Moreover, immunohistochemistry technique can be used to evaluate the expression of the CASR in the tissues samples from CRC patients with different stages and correlate them with disease progression.

\section{ACKNOWLEDGMENTS}

This project was funded by the Deanship of Scientific Research (DSR), at King Abdulaziz University, Jeddah, under grant no. J-61-247-38. The author, therefore, acknowledges with thanks DSR technical and financial support.

Deceleration of interest: None

\section{REFERENCES}

1. Brennan SC, Thiem U, Roth S, Aggarwal A, Fetahu IS, Tennakoon $\mathrm{S}$, et al. Calcium sensing receptor signalling in physiology and cancer. Biochim Biophys Acta. 2013;1833(7):1732-1744. doi: 10.1016/j. bbamcr.2012.12.011. 
2. Brown EM, MacLeod RJ. Extracellular calcium sensing and extracellular calcium signaling. Physiol Rev. 2001;81:239-297. doi: 10.1152/ physrev.2001.81.1.239.

3. Riccardi D, Brown EM. Physiology and pathophysiology of the calcium-sensing receptor in the kidney. Am J Physiol Renal Physiol. 2010;298(3):F485-F499. doi: 10.1152/ajprenal.00608.2009.

4. Kallay E, Wrba F, Cross HS. Dietary calcium and colon cancer prevention. Forum Nutr. 2003;56:188-190.

5. Geibel JP, Hebert SC. The functions and roles of the extracellular $\mathrm{Ca}^{2+}$-sensing receptor along the gastrointestinal tract. Annu Rev Physiol. 2009;71:205-217. doi: 10.1146/annurev.physiol.010908.163128.

6. van Abel $M$, Hoenderop JG, van der Kemp AW, van Leeuwen JP, Bindels RJ. Regulation of the epithelial $\mathrm{Ca} 2+$ channels in small intestine as studied by quantitative mRNA detection. Am J Physiol Gastrointest Liver Physiol. 2003;285(1):G78-G85 doi: 10.1152 /ajpgi.00036.2003.

7. Chikatsu N, Fukumoto S, Takeuchi Y, Suzawa M, Obara T, Matsumoto T, et al. Cloning and characterization of two promoters for the human calcium-sensing receptor (CaSR) and changes of CaSR expression in parathyroid adenomas. J Biol Chem. 2000;275(11):7553-7557. doi: 10.1074/ jbc.275.11.7553.

8. Alsanea N, Abduljabbar AS, Alhomoud S, Ashari LH, Hibbert D, Bazarbashi S. Colorectal cancer in Saudi Arabia: incidence, survival, demographics and implications for national policies. Ann Saudi Med. 2015;35(3):196-202. doi: 10.5144/0256-4947.2015.196.

9. Zubaidi AM, AlSubaie NM, AlHumaid AA, Shaik SA, AlKhayal KA, AlObeed OA. Public awareness of colorectal cancer in Saudi Arabia: A survey of 1070 participants in Riyadh. Saudi J Gastroenterol. 2015;21(2):78-83. doi: 10.4103/1319-3767.153819.

10. Van der Meer R, De Vries HT. Differential binding of glycine-and taurine-conjugated bile acids to insoluble calcium phosphate. Biochem J. 1985;229(1):265-268.

11. Fedirko V, Bostick RM, Flanders WD, Long $Q$, Sidelnikov E, Shaukat A, et al. Effects of vitamin and calcium on proliferation and differentiation in normal colon mucosa: a randomized clinical trial. Cancer Epidemiol Biomarkers \& Prev. 2009;18(11):2933-2941. doi: 10.1158/1055-9965.EPI-09-0239.

12. Zeleznikova V, Vedralova M, Kotrbova-Kozak A, Zoubkova $\mathrm{H}$, Cerna M, Rychlik I. The intron 4 polymorphism in the calcium-sensing receptor gene in diabetes mellitus and its chronic complications, diabetic nephropathy and non-diabetic renal disease. Kidney Blood Press Res. 2014;39(5):399-407. doi: 10.1159/000368453.

13. Mahmoudi T, Karimi K, Arkani M, Farahani H, Nobakht $\mathrm{H}$, Dabiri R,et al. Parathyroid hormone gene rs6256 and calcium sensing receptor gene rs1801725 variants are not associated with susceptibility to colorectal cancer in Iran. Asian Pac J Cancer Prev. 2014;15(15):6035-6039. doi: 10.7314/ APJCP.2014.15.15.6035.
14. Han C, Shin A, Lee J, Lee J, Park JW, Oh JH, et al. Dietary calcium intake and the risk of colorectal cancer: a case control study. BMC Cancer. 2015;15:966. doi:10.1186/ s12885-015-1963-9.

15. Booth GC, Zhang Z, Shannon J, Bobe G, Takata Y. Calcium intake and cancer risk: current evidence and future research directions. CurrNutr Rep. 2017;6(2):72-79. doi:10.1007/ s13668-017-0193-y.

16. Reid IR, Bristow SM, Bolland MJ. Calcium supplements: benefits and risks. J Intern Med. 2015;278(4):354-368. doi: 10.1111/joim.12394.

17. Worzfeld T, Wettschureck N, Offermanns S. G(12)/ G(13)-mediated signaling in mammalian physiology and disease. Trends Pharmacol Sci. 2008;29(11):582-589. doi: 10.1016/j.tips.2008.08.002.

18. Huang C, Hydo LM, Liu S, Miller RT. Activation of choline kinase by extracellular $\mathrm{Ca}^{2+}$ is $\mathrm{Ca}\left({ }^{2+}\right)$-sensing receptor, Galpha12 and Rho-dependent in breast cancer cells. Cell Signal. 2009;21(12):1894-1900. doi: 10.1016/j. cellsig.2009.08.004.

19. Ward DT, Riccardi D. New concepts in calcium-sensing receptor pharmacology and signalling. Br J Pharmacol. 2012;165(1):35-48. doi: 10.1111/j.1476-5381.2011.01511.x.

20. Aggarwal A, Prinz-Wohlgenannt M, Tennakoon S, Hobaus J, Boudot C, Mentaverri R, et al. The calcium-sensing receptor: A promising target for prevention of colorectal cancer. Biochim Biophys Acta. 2015;1853(9):2158-2167. doi: 10.1016/j.bbamcr.2015.02.011.

21. D'Souza-Li L. The calcium-sensing receptor and related diseases. Arq Bras Endocrinol Metabol. 2006;50(4):628-639. doi: 10.1590/S0004-27302006000400008.

22. Yano S, Sugimoto T, Kanzawa M, Tsukamoto T, Hattori T, Hattori S, et al. Association of polymorphic alleles of the calcium-sensing receptor gene with parathyroid hormone secretion in hemodialysis patients. Nephron. 2000;85(4):317323. doi: $10.1159 / 000045681$

23. Wang L, Widatalla SE, Whalen DS, Ochieng J, Sakwe AM. Association of calcium sensing receptor polymorphisms at rs1801725 with circulating calcium in breast cancer patients. BMC Cancer. 2017;17:511. doi: 10.1186/s12885-017-3502-3.

24. Dabiri R, Mahmoudi $T$, Farahani $H$, Nobakht $H$, Zali MR. Alanine to serine at position 986 of calcium sensing receptor and colorectal cancer risk. Iran J Cancer Prev. 2016;9(4):e8098. doi: 10.17795/ijcp-8098.

25. Masvidal L, Iniesta R, Casala C, Galvan P, Rodriguez E, Lavarino $\mathrm{C}$, et al. Polymorphisms in the calcium-sensing receptor gene are associated with clinical outcome of neuroblastoma. PLoS One. 2013;8(3):e59762. doi: 10.1371/ journal.pone.0059762. 